\title{
ELECTROMAGNETIC LOADS ON ITER IN-VESSEL COMPONENTS*
}

\author{
D. E. Williamson, D. L. Conner, B. E. Nelson, R. O. Sayer, and J. J. Yugo \\ Martin Marietta Energy Systems, Inc. \\ CONF-910968--14 \\ Post Office Box 2009 \\ Oak Ridge, Tennessee 37831-8055 \\ DE92 000672
}

\begin{abstract}
Design of the vacuum vessel and internal blanket/shield modules for the International Thermonuclear Experimental Reactor (ITER) is strongly influenced by the magnitude of electromagnetic loads duc to plasma disruption. Calculations with the finite element code, EddyCuFF, have been performed to quantify these loads and incorporate them into the design process. A multifilament model of plasma motion and current decay has been developed using data generated by the Tokamak Simulation Code (TSC). Comparison with: calculations cmploying singlc filament plasma models illustrates the need to use self-consistent, distributed plasma scenarios when analyzing toroidally segmented components. Application is made lo design and analysis of the high aspect ratio design (HARD) option vessel and blanket/shield modules. Variations in geometry, response characteristics. and electromagnetic loads are compared to the reference design values.
\end{abstract}

\section{Introduclion}

Electromagnetic forces due to plasma disruption impose strong requirements on the electrical and structural components of ITER. During the Conceptual Design Aclivities (CDA) phase of the project, henchmark analyses were performed to determine the effect of not only disruption parameters, such as motion and plasma decay rate, but also differences in geometry and ficld drivers used by the analysis codes [1]. Results indicate that modeling to accomodate three-dimensional effects and the use of self-consistent plasma disruption scenarios can have a significant effect on the accuracy of force distributions for structural analysis.

Calculations with the finile clement code. EddyCuFF [2]. have been performed to quantify these effects and incorporate them into current design activitics. EddyCuFF determines the nodal current and force distribution on a shell element representation of the three-dimensional conducting structure. Eddy current heating and clectromagnelic loads are applied to a structural analysis model to detcrmine transient stress and deflection. A distributed plasma model, based on reference design geometry, has been developed to cvaluate its effect on the in-vessel components and a thin-wall vacuum vessel concept. Results are compared with single filament models and the ITER benchmark reference values.

Application of the analysis method has been made to design

\footnotetext{
- Research sponsored by the Office of Fusion Energy, U.S. Department of Energy. under contract DE-AC05-84OR21400 with Mantin Mariella Energy Sysiems, Inc.
}

and analysis of the high aspect ratio design (HARD) option vessel and blanket/shield modules. Variations in geometry, response characleristics. and electromagnetic loads are compared to the reference design values.

\section{Distributed Plasma Model}

Studies by R. Albenese el al. [3] have shown that the shape and distribution of plasma current in a disnupiion simulation can have a significant effect on the calculated loads for segmented struclures, such as the blankel/shield modules. To evaluate this effect, a multi-filament model of plasma current decay was developed using data generated by the Tokannak Simulation Code (TSC) [4.5]. This physics code employs a numerical model of an axisymmetric plasma and surrounding structure to determine self-consistent plasma behavior diring disruption. Fig. 1 shows a TSC computational grid with vacuum vessel, inboard and outboard blanket/shield modules, and other conducting structure represented by axisymmetric filaments. Toroidal segmentation of the blanket modules is moleled by use of a common resislive gap. The resulting current history for the 2500 ccll grid is reduced to approximately 550 filaments for EddyCuFF, including poloidal field coils, active iontrol coils, and internal structure not included in the EddyCuFF model.

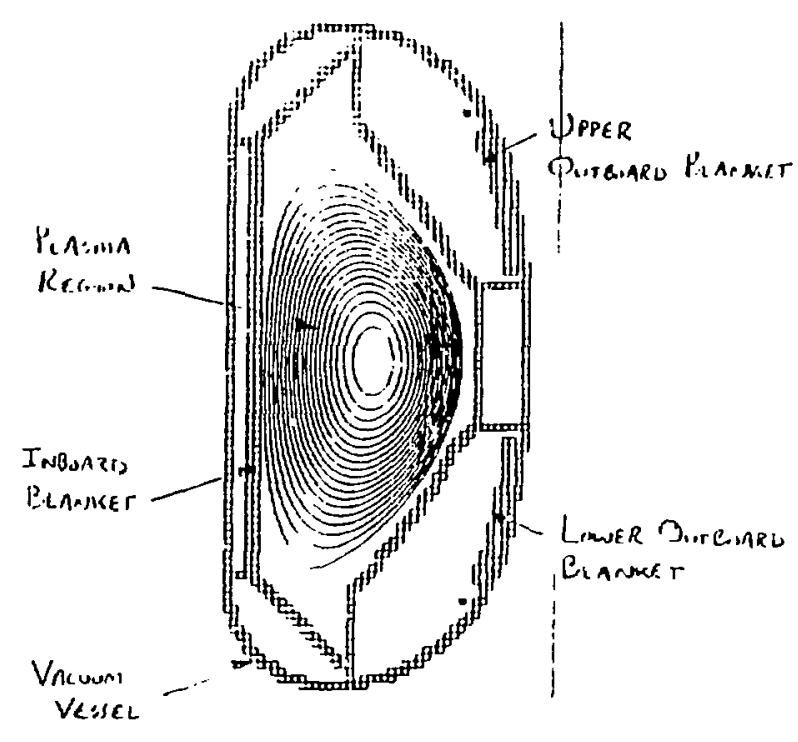

Fig. 1. TSC code axisymmetric plasma model 
EddyCuFF calculations were performed for the inboard blanket/shicld modules, an assembly of 96 steel boxes connected to thick back plates to form 32 modules in the torus (Fig 2). The toroidally segemented blarikets are subject to large vertical loads. from the interactio:) of circulaling current with toroidal field, and large radial forces caused by saddle currents in the first wall.

A 22 MA plasma simulation, with an initial vertical displacement of $1 \mathrm{~m}$ and decaying at a rate of $1 \mathrm{MA} / \mathrm{ms}$, was used to develop the distributed current driver [5]. As can be seen in Table 1. the distributed plasma has a large and beneficial effect on both radial and vertical loads. This is dus primarily to an elongation of poloidal field lines in the distributed plasma that reduces the angle of incidence with the first wall and generation of saddle currents in the structure. The effect of a distributed plasma model on vacuum vessel forces is small.

\section{Application to HARD}

The high aspect ratio design option for ITER affects many important load parameters. such as the size and position of components, response characteristics, and the magnitude of driving ficlds. Using both single filament and distributed plasma models, calculations have boen performed to quantify these effects and compare them to the reference design.

Fig. 3 illustrates the main geometric differences between HARD and the reference design, including 1) a smaller vacuum vessel cross-section with larger major radius, 2) inboard blanket closer to the plasma center, and 3) larger outhoard blanket cross-section. Othat parameters, such as segmentation of the blanket mociules, gap dimensions, and material thicknesses are assumed to be identical to the reference design. Magnetic field differenc ss are duc to a

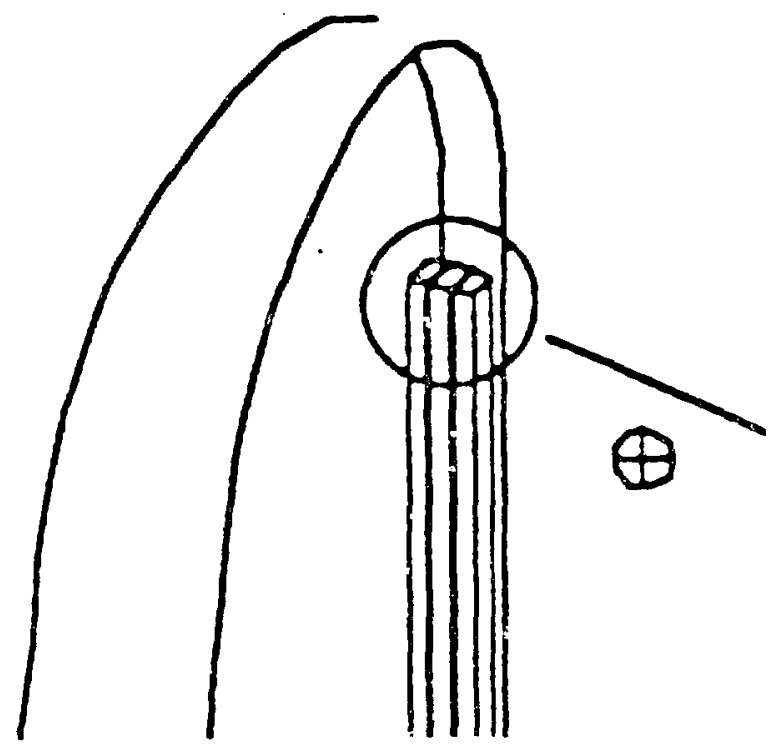

Fig. 2. EddyCuFF Benchı.rark Gcometry Model
Table 1 - Distributed Plasma Model Results

\begin{tabular}{|lccc|}
\hline $\begin{array}{l}\text { Disruption } \\
\text { Model }\end{array}$ & $\begin{array}{l}\text { Net Circulating } \\
\text { Curtent (MA) }\end{array}$ & $\begin{array}{c}\text { F-Rad on 1/4 } \\
\text { Geom (MN) }\end{array}$ & $\begin{array}{c}\text { F-Ver Gil 1/2 } \\
\text { Geom (MN) }\end{array}$ \\
$\begin{array}{l}\text { TSC 0705 [5] } \\
\text { Single Fil. }\end{array}$ & TBD & TBD & TBD \\
$\begin{array}{l}\text { TSC 0705 } \\
\text { Mulii-Fil. }\end{array}$ & 0.7 & 0.9 & 2.4 \\
$\begin{array}{l}\text { ITER Ref. [1] } \\
\text { Single Fil. }\end{array}$ & 1.3 & 1.0 & 3.0 \\
\hline
\end{tabular}

lower plasma current and higher toroidal field for the HARD option. Table 2 summarizes the main electromagnetic parameters for the two designs.

\section{Vacuum Vessel}

Calculations were performed for an axisymmetric, uniform thickness vessel with $100 \mathrm{~ms}$ lime constant similar to previous ITER analysis models. As distributed plasma cffects are small for the vessel, a single filament plasma centered at $R=6.33 \mathrm{~m}, \mathrm{Z}=-1.0 \mathrm{~m}$ with an exponential current decay of various lengths was assumed.

The analysis showed that induced current in the toroidally continuous vessei varics from $5.9 \mathrm{MA}$ for a $0.2 \mathrm{MA} / \mathrm{ms}$ disruption to $13.1 \mathrm{MA}$ for a $3.0 \mathrm{MA} / \mathrm{ms}$ decay. When tabulated as percent of initial plasma current (Table 3 ). this variation follows closely the values for the reference design and suggests that small calculational differences in geometry. plasma currenı distribution, and PF coil currents have only a small effect on induced current compared to the effect of L/R time for the structure.

The var.ation of net radial and vertical forces with decay time is shown in Fig. 4-5. For a 1 MA/ms current decay, radial

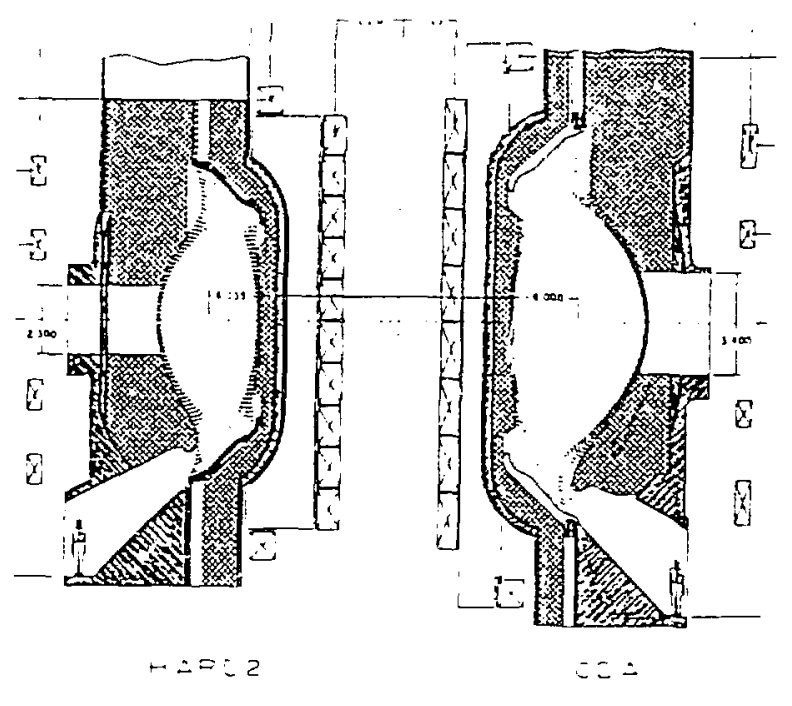

Fig. 3. Elevation view of $H A R D$ and CDA configurations 
Table 2 - Comparison of Electromagi.ctic Paramelers

\begin{tabular}{|lll|}
\hline Parameter & ITER & HARD \\
Major Radius (m) & 6.00 & 6.33 \\
Plasma Current (MA) & 22.0 & 14.9 \\
Decay Rate (MA/ms) & $1-3$ & 1.3 \\
Vessel L/R Time (ms) & 100 & 100 \\
Vessel Resistance $(\mu \Omega)$ & 20 & $>20$ \\
Toroidal Field @Ro $(\mathrm{T})$ & 4.85 & 7.11 \\
\hline
\end{tabular}

Table 3 - Percent of Plasma Current Induced in Vessel

\begin{tabular}{|ccc}
\hline Decay Rate (MA/ms) & TTER & HARD \\
4.0 & $89 \%$ & $85 \%$ \\
1.0 & $79 \%$ & $71 \%$ \\
0.2 & $50 \%$ & $40 \%$
\end{tabular}

1. CARIDDI 3D Analysis [1]

2. EddyCuFF Model

forces are redused by approximately the ratio of plasma currents squared, from $-45 \mathrm{MN} / \mathrm{radian}$ (20 $\mathrm{MN}$ per $1 / 16$ sector) to $-22 \mathrm{MN} /$ radian (12 MN). Maximum vertical force is reduced from $9 \mathrm{MN} / \mathrm{radian}$ to $4.6 \mathrm{MN} / \mathrm{radian}$.

\section{In-Vessel Components}

The magnitude of current induced in the inbcard blankel/shield modules is affected by changes in size, position, and magnetic field. As shown in Fig. 6, a decrease in poloidal field at the center of the inboard module is offset by an increase in radial position and Mux area per electrical segmient. The result is no change in driving voltage, but a $20 \%$ decrease in circulating current since the loop resistance is higher (Fig. 7). Inboard passive stabiiity plates, which may be required for plasma control in the HARD configuration, would increase the induced current to 3.5 MA. Toroidal field at the center of each module is increased from 8.5 T to $10.5 \mathrm{~T}$, but the interaction with reduced circulating and saddle currents produces only a small increase in fores acting on a quarter of the geometry (Fig. 8). Nei radial and vertical loads on a module are unchanged.

The larger outboard blanke/shield module for HARD has a $50 \%$ higher driving voltage to induce circulating currents, but a higher loop resistance, so that induced currents are only slightly higher than in the reference design. Toroidal field at the center of a module is increased from $3.5 \mathrm{~T}$ to $5 \mathrm{~T}$. however, which leads to a $40 \%$ increase in radial and vertical loads on a quarter module. Vertical loads are also increased by the interaction of toroidal field with longer radial current paths around the box. A summary of force results is given in Table 4.

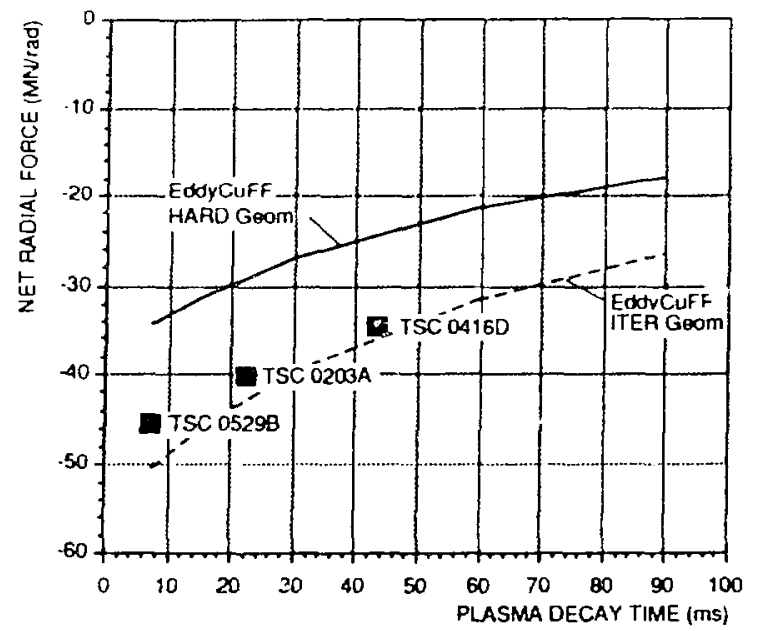

Fig. 4. Variation of Net Radial Force with Decay Time

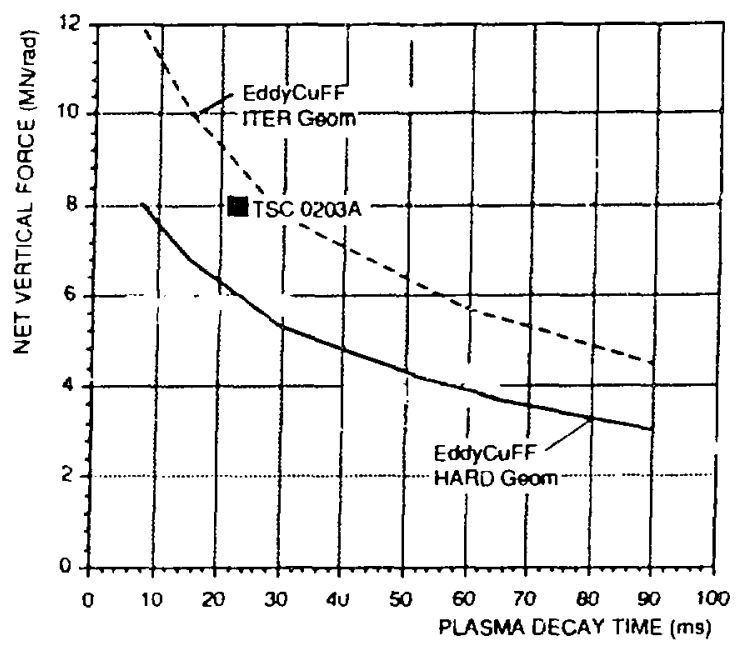

Fig. 5. Variation of Net Vertical Force with Decay Time

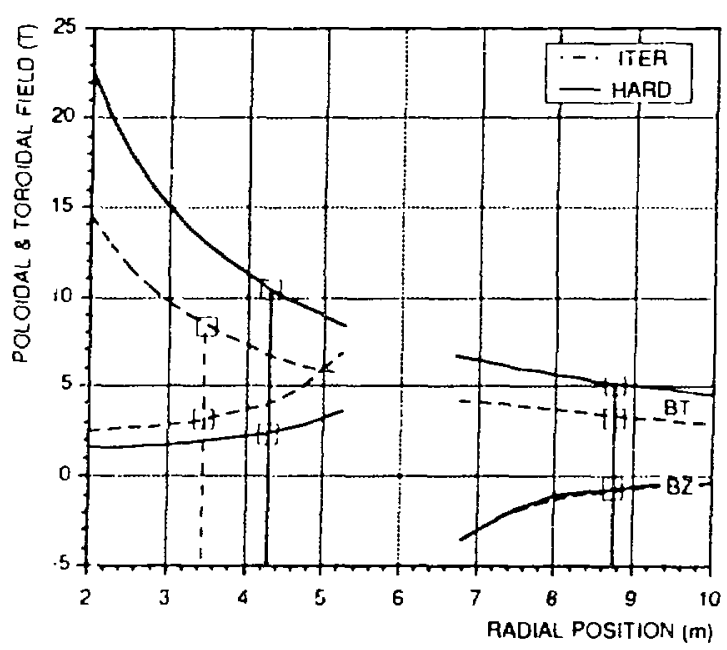

Fig. 6. Magnetic Field at Center of Blanket Modules 


\section{Conclusion}

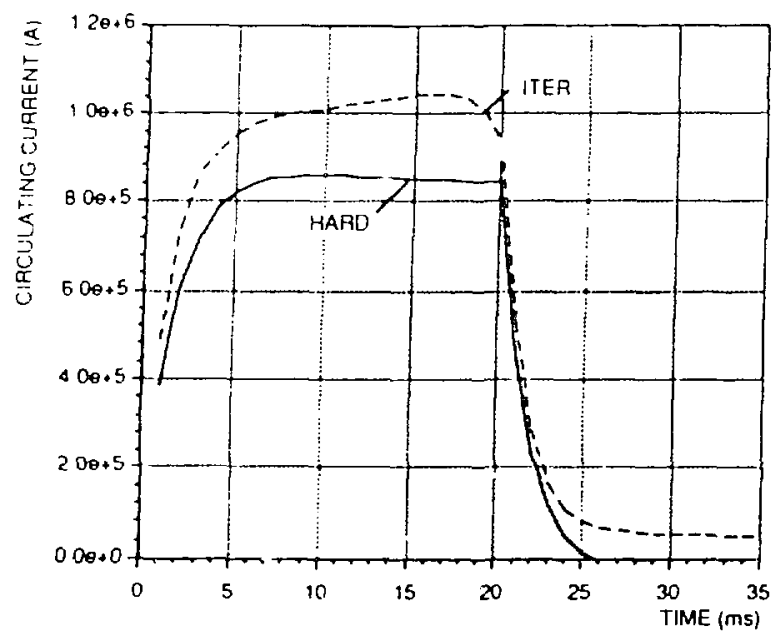

Fig. 7. Induced Current in Inboard Module

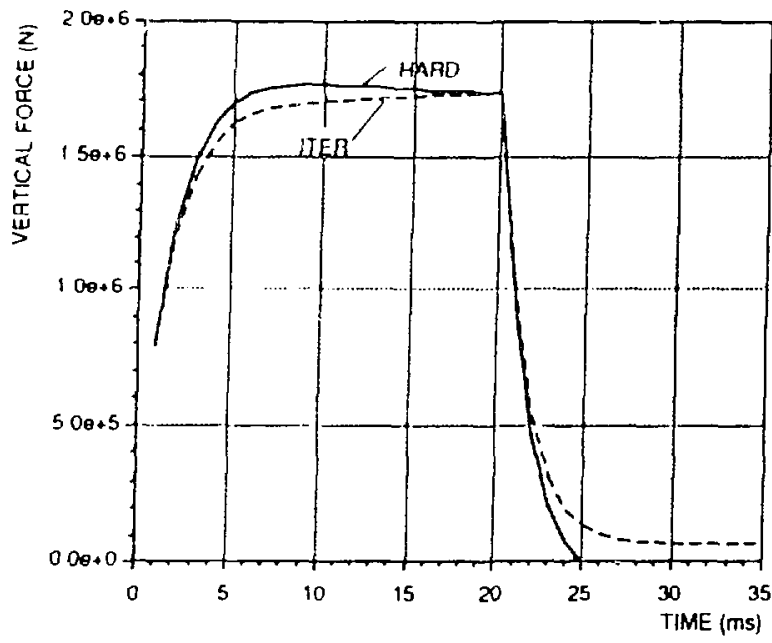

Fig. 8. Radial and Vertical Loads on Segment of Module

Table 4 - Comparison of Blanket/Shield Module Forces

\begin{tabular}{|lcc|}
\hline Parameter & ITER [1] & HARD \\
Inboard Blanket & & \\
F-Rad on I/4 Box (MN) & 0.7 & 0.8 \\
Wiit Stability Loops (MN) & & 3 \\
F-Ver on 1/2 Box (MN) & 2.5 & 2.6 \\
With Stability Loops (MN) & & 9 \\
& & \\
Outboand Blanket & 10 & TBD \\
F-Rad on 1/4 Box (MN) & 28 & TBD \\
F-Vert on I/2 Box (MN) & & \\
& & \\
Vacuum Vessel & -45 & -22 \\
Max F-Rad (MN/radian) & 9 & 5 \\
Max F Vert (MN/radian) & 9 \\
\hline
\end{tabular}

A method has been developed to incorporate self consistent, distributed plasma drivers into three dimensional eddy current calculations. Comparison with single filament models accentuates the need to do so when analyzing torojdally segmented components. Application of EddyCuFF to the high aspect ratio design option has shown that reduced plasma current has a beneficial effect on disruption loads for the vacuum vessel. Reduced current in the inboard blanket/shıeld module is offset by higher toroidal field, but the end result is no change in local or global forces. Outboard blanket forces are increased locally over the reference design.

\section{Reference}

[1] Y. Shimomura et al.. ITER Poloidal Ficld System. ITER Documentation Series, No. 27. Vienna, 1991

[2] A. Kameari, Transient Eddy Current Analysis on Thin Conductors with Arbitrary Connections and Shapes, Joumal of Computational Physics, 42, 124-140 (1981)

[3] R. Albenese et al., Electromagnetic Effects Induced by Plasma Disruptions in the NET Vacuum Vessel, Fusion Enginoering and Design, 1991

[4] S. Jardin et al., Dynamic Modeling of Transport and Positional Control of Tokamaks. Joumal of Computational Physics, 66, 481-507 (1986)

[5] R. Saycr, ITER Disruption Modeling with TSC. ITER-IL-PF-4-0. July 1990

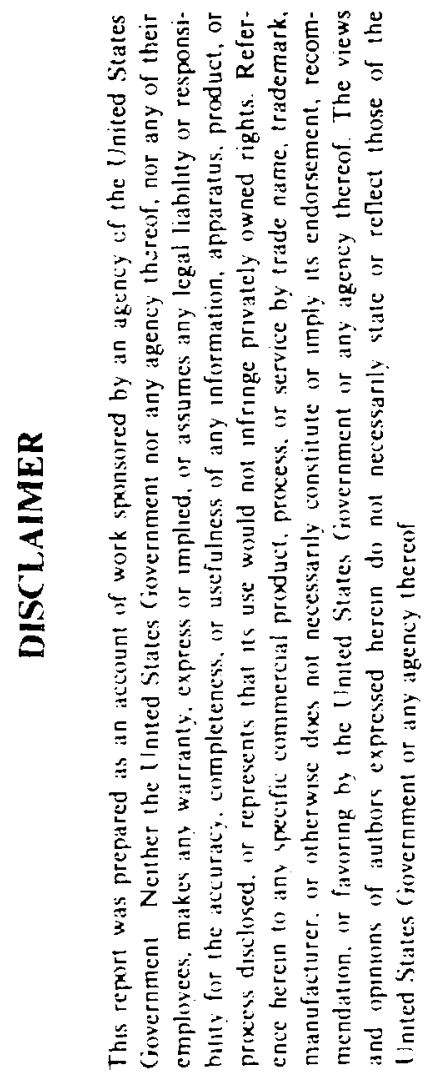

